\title{
THE EFFEGT OF HCG OR ENDOGENOUS GONADOTROPHIN ON NORMAL BOVINE FOLLIGULAR ACTIVITY
}

\author{
HILARY DOBSON AND R. J. FITZPATRICK \\ Department of Veterinary Clinical Studies, University of Liverpool, \\ Leahurst, Neston, Cheshire
}

(Received 9th October 1974)

In veterinary clinical practice, $\mathrm{HCG}$ is widely used as a commercially available substitute for $\mathrm{LH}$ to induce follicular rupture and CL formation in infertile cows. The present study was undertaken to determine the effect of HCG on ovarian function in normal cows before conducting a similar investigation in infertile animals.

The HCG was administered before the expected increase in endogenous $\mathrm{LH}$ concentration at oestrus and the effect on oestradiol-17 $\beta$ concentration in jugular venous blood was monitored. Hormonal changes occurring during the endogenous release of gonadotrophins at normal oestrus in the cow were also studied.

Blood samples were collected into heparinized evacuated bottles from the jugular veins of eight untreated control Friesian cows every $4 \mathrm{hr}$ during the oestrous period. A group of five experimental cows were bled twice daily at 08.00 and 17.30 hours, starting approximately 3 days before the expected day of HCG injection, then every $2 \mathrm{hr}$ after injection for a further $42 \mathrm{hr}$. In all cows, GL development was followed by taking blood samples every 3rd day for 21 days. The samples were centrifuged as soon as possible after collection and the plasma was stored at $-15^{\circ} \mathrm{C}$. Oestradiol- $17 \beta$, progesterone and LH concentrations were measured by radioimmunoassay (RIA) as previously described (Dobson, Cooper \& Furr, 1975); HCG did not cross-react appreciably with the anti-bovine LH serum.

Due to the variation in length of the oestrous cycle, 18 to 21 days, it was difficult to time the HCG injection to precede the release of endogenous LH and yet allow the oestradiol-17 $\beta$ concentration to increase significantly above basal values. Since the plasma progesterone concentration declines before oestrus (Dobson, Boyd \& Exley, 1973), each plasma sample was assayed by a 'quick' progesterone RIA immediately after collection. These 'quick' assays were restricted to three points for each standard curve $(0,200$ and $500 \mathrm{pg})$ and to an antibody-antigen incubation time of $2 \mathrm{hr}$. When plasma contained $3 \mathrm{ng}$ progesterone/ml, or less, a dose of HCG was administered within the next $24 \mathrm{hr}$. The dose used was either 1500 or 3000 i.u. HCG (Chorulon: Intervet), administered as a single intravenous injection to each of five cows. After each experiment, every cow was allowed an uninterrupted cycle and then received the alternative dose of HCG in a repeat experiment. 
Typical changes in the hormonal concentrations in jugular plasma that occurred around natural oestrus are shown in Text-fig. 1. Similar results were obtained in the other seven cows. A decrease in progesterone concentration from mid-luteal values of $6 \mathrm{ng} / \mathrm{ml}$ to values at oestrus of $<1 \mathrm{ng} / \mathrm{ml}$ was accompanied by an increase in oestradiol- $17 \beta$ from $6 \mathrm{pg} / \mathrm{ml}$ to $15 \mathrm{pg} / \mathrm{ml}$ at the onset of oestrus. The sudden and transient increase in $\mathrm{LH}$ concentration from $1 \mathrm{ng} / \mathrm{ml}$ to $>20 \mathrm{ng} / \mathrm{ml}$ was concurrent with a decline in the concentration of oestradiol-
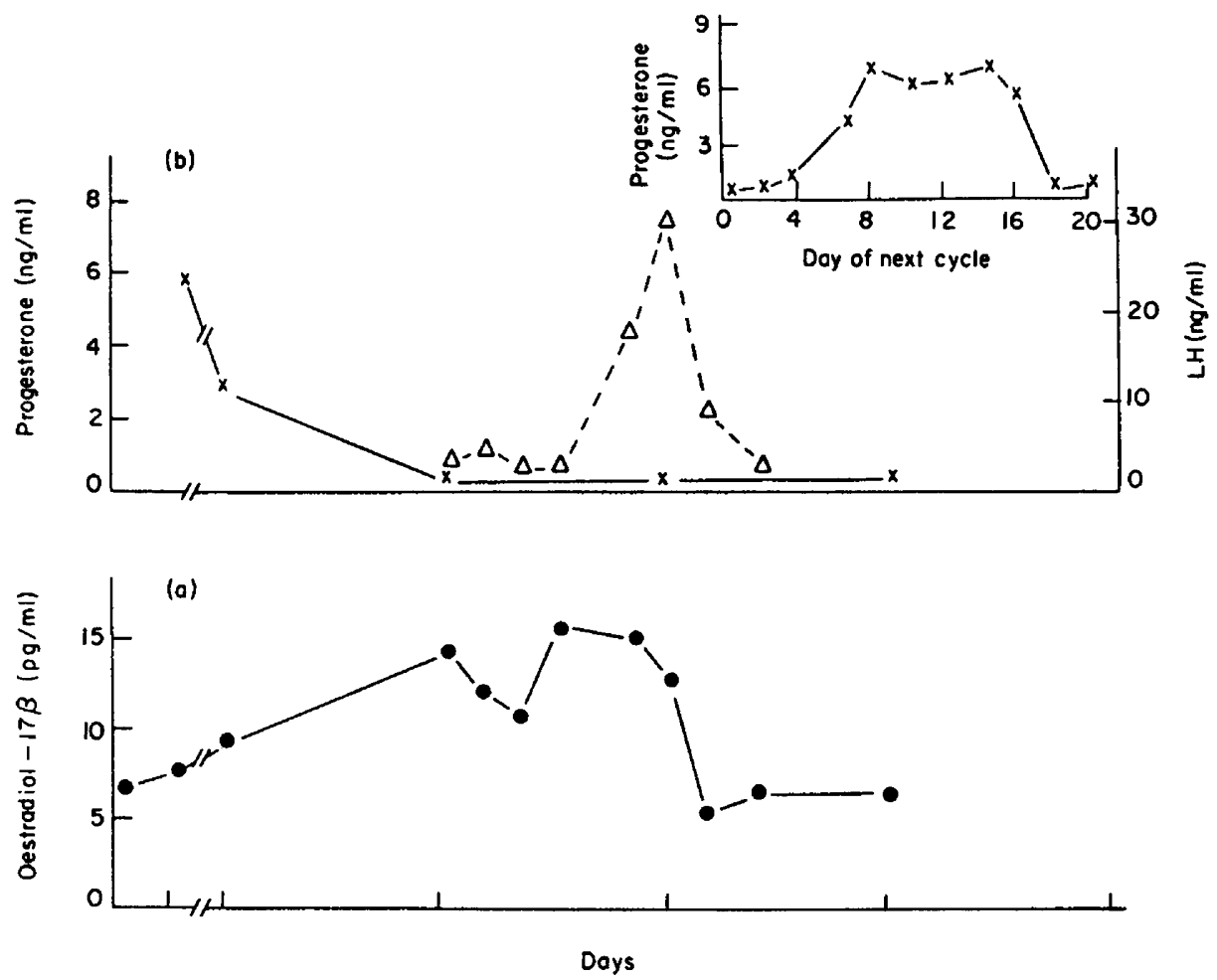

TEXT-FIG. 1. Jugular venous plasma concentrations of (a) oestradiol-17 $\beta$ ( $\bullet$ ) and (b) progesterone $(x)$ and $\mathrm{LH}(\Delta)$ during the normal oestrous period of a cow. The insert shows the progesterone concentrations for the next 20 days.

$17 \beta$ to 'pre-oestrus' values of $5 \mathrm{pg} / \mathrm{ml}$. Ovulation, determined by rectal palpation, occurred on average $25 \mathrm{hr}$ after the $\mathrm{LH}$ surge in the eight control cows. Subsequent CL development was normal, as shown by plasma progesterone concentrations.

For the first three experiments, HCG was not given until the day after plasma progesterone values of 2.0 to $1.5 \mathrm{ng} / \mathrm{ml}$ were obtained; this proved to be too late for HCG to precede the endogenous LH peak so that it was difficult to assess the effect of HCG alone in these cases. Subsequently, a higher concentration of progesterone $(3.0 \mathrm{ng} / \mathrm{ml})$ was used as the criterion for the timing of HCG injection. Text-fig. 2 shows the results obtained from HCG injection in the six experiments which gave consistent results. There was a significant decline $(P<0.02$, by Student's $t$ test $)$ in oestradiol $-17 \beta$ concentration by the 12 th hour 


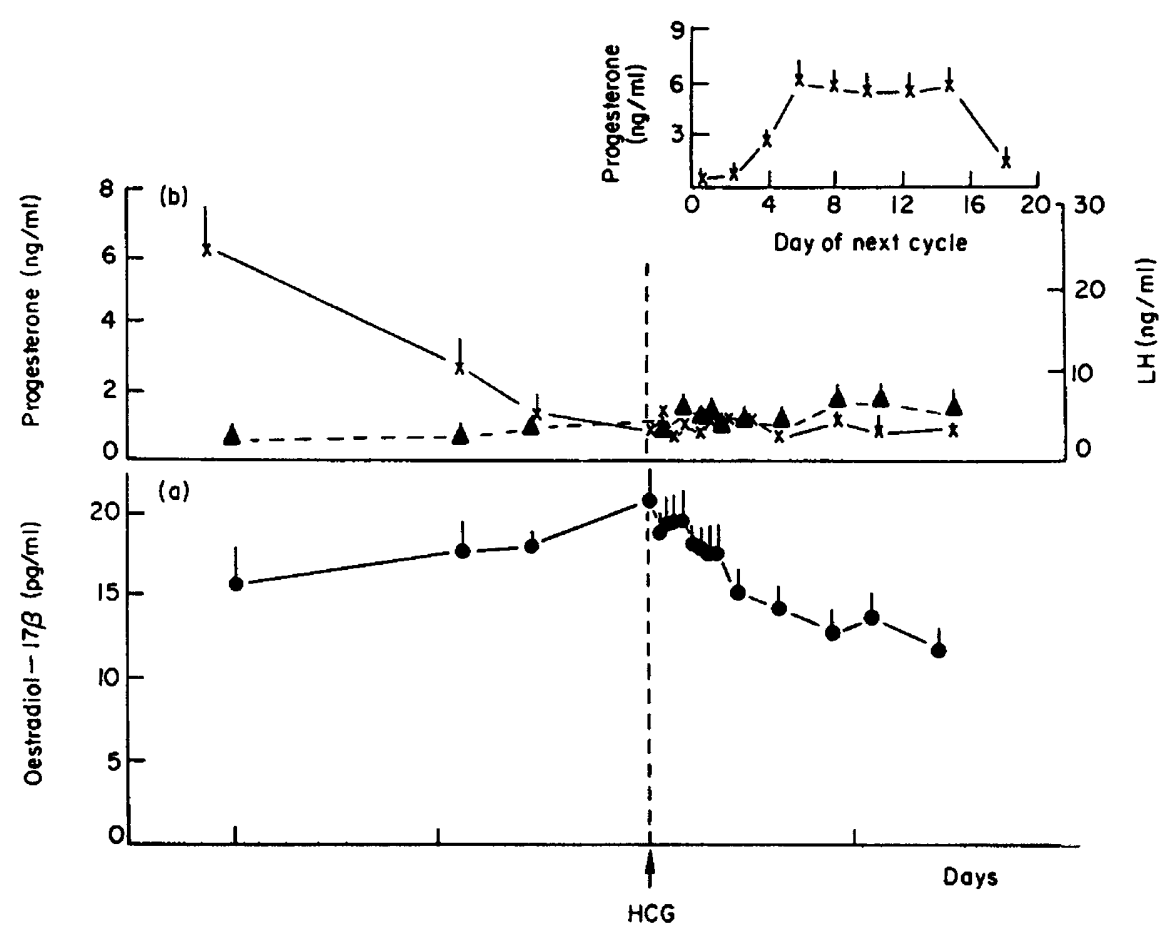

TExT-Fig. 2. Mean jugular venous plasma concentrations of (a) oestradiol-17 $\beta$ ( $\bullet$ ) and (b) progesterone $(x)$ and LH $(\Delta)$ during treatment with HCG in six experiments. The insert shows the progesterone concentrations for the next 20 days. Vertical bars represent S.E.

after administration of either dose of HCG in nine experiments, the exception being one cow which did not respond by a decrease in oestradiol-17 $\beta$ or by production of a functional CL. The present study in the cow in vivo confirms work in vitro in which LH caused a precipitous drop in oestrogen secretion by cultured sheep follicles (McIntosh \& Moor, 1973).

After HCG injection in the six successful experiments, there was no significant increase in endogenous LH concentration before ovulation. For these animals, the mean time interval \pm S.E. between a plasma progesterone concentration $<3 \mathrm{ng} / \mathrm{ml}$ and the HCG injection was $22 \pm 4 \mathrm{hr}$ compared to $74 \pm 7 \mathrm{hr}$ between $<3 \mathrm{ng} / \mathrm{ml}$ and the LH surge in the control animals. This suggests that there is an optimum period for which oestradiol-17 $\beta$ must predominate over progesterone to cause release of LH from the pituitary.

While it has been inferred that the absence of an endogenous LH surge was due to a decreased oestradiol-17 $\beta$ influence on the hypothalamic-pituitary axis, no evidence has been included in this communication to exclude a short feedback mechanism whereby HCG directly influences pituitary synthesis or release of $\mathrm{LH}$ as suggested for the rat (Döcke \& Glaser, 1971). Further work is necessary to clarify this position in the cow.

In the absence of an endogenous LH surge, HCG usually appeared to initiate normal luteinization as indicated by subsequent progesterone concentrations 
similar in duration and magnitude to those in the untreated cows. In one cow, however, sub-normal plasma progesterone concentrations were recorded after 1500 i.u. HCG; after 3000 i.u. HCG, a CL was established in the same animal, but regression occurred earlier than in untreated normal cows, with progesterone reaching basal concentrations by Day 14 after administration of HCG.

The expenses for this project were defrayed by grants from the A.R.C. and Animal Health Trust to whom the authors express gratitude. One of us (H.D.) is an Animal Health Trust Wooldridge Fellow. The authors are indebted to Dr L. E. Reichert, Jr, for the purified bovine LH used for radioiodination, to Dr W. Hansel for the anti-bovine LH serum, to N.I.H. for purified bovine LH standards and to Dr B. J. Furr for the anti-progesterone serum.

\section{REFERENCES}

Dobson, H., Boyd, L. J. \& ExLEy, D. (1973) Circulating oestrogens and progesterone in the bovine after synchronization with melengestrol acetate. F. Reprod. Fert. 33, 231-237.

Dobson, H., Cooper, M. J. \& FURr, B. J. A. (1975) Synchronization of oestrus with I.C.I. 79,939, an analogue of $\mathrm{PGF}_{2 \alpha}$ and associated changes in plasma progesterone, oestradiol-17 $\beta$ and $\mathrm{LH}$ in heifers. F. Reprod. Fert. 42, 141-144.

Döcke, F. \& Glaser, D. (1971) Internal feedback of luteinizing hormone in cyclic female rats. $\mathcal{F}$. Endocr. 51, 403-404.

MaInTosh, J. E. A. \& Moor, R. M. (1973) Regulation of steroid secretion in sheep ovarian follicles. 7. Reprod. Fert. 35, 605-606. 